\title{
Integrated regional assessment and climate change impacts in river basins
}

\author{
Brent Yarnal* \\ Department of G eography and Center for Integrated Regional Assessment, The Pennsylvania State University, \\ University Park, Pennsylvania 16802, USA
}

\begin{abstract}
Integrated regional assessment of climate change is an interdisciplinary, iterative process that involves scientific, policy, and societal stakeholders. The goal of integrated regional assessment is to promote a better understanding of, and more informed decisions on, how locales and regions contribute to and are affected by climate change. The purpose of the paper is to explain what integrated regional assessment is and how it is being used by practitioners. It aims to promote this approach by offering a more comprehensive account of integrated regional assessment than has been presented before. The article uses the integrated assessment of climate change impacts in river basins to provide a concrete regional basis for discussion. Case studies of 3 integrated assessments of river basins are presented to demonstrate the value of this approach. It is argued that when integrated regional assessment works, it provides an ideal way of bringing together science, society, and policy to face the challenges of climate change.
\end{abstract}

KEY WORDS: Integrated regional assessment · Integrated assessment · Climate change impacts · River basins $\cdot$ Hydrology $\cdot$ Water resources

\section{INTRODUCTION}

Traditionally, the emphasis of the global change research community has been on understanding global-scale aspects of climate change. However, there has been a growing interest in the regional and local implications of climate change. For example, the United States Global Change Research Program identified 3 key challenges for research in the coming decade (USGCRP 1998):

- Developing regional-scale estimates of the timing and magnitude of climate change.

- Advancing regional analyses of the environmental and socioeconomic consequences of climate change in the context of other stresses.

- Conducting integrated assessments of the environmental and societal implications of climate change.

The motivation for regionally and locally specific climate change information comes from 2 related quar-

*E-mail: alibar@essc.psu.edu ters. First, society in general and decision makers in particular are demanding more socially relevant science (Yarnal 1996). Second, early impacts studies (e.g. Titus et al. 1991) suggested that impacts could be severe in some regions, thus raising the concerns of decision makers representing local constituencies. Although more recent research on the physical manifestations of climate change (Houghton et al. 1996) suggests that the early scenarios were probably exaggerated, the understanding that ' $g$ lobal warming' is a regional to local problem has taken root.

Integrated regional assessment is an immature research area attempting to appraise the regional details of global climate change and other global changes. The goal of this paper is to introduce and explain this regional approach to climate change research. To reach this goal, it is necessary to define the older, more inclusive model of integrated assessment of climate change and to show how integrated regional assessment is the regional form of that model. The paper will illustrate integrated regional assessment by presenting examples of research involving 
climate change impacts in 3 river basins. As necessary background, a case is made for using river basins as the unit of analysis, and the literature linking climate change, hydrology, and water resources is reviewedagain with the emphasis on river basins. The discussion points out notable features brought forth by the 3 case studies, and concludes that integrated regional assessment is a valuable framework to help places prepare for climate change.

\section{INTEG RATED ASSESSMENT OF CLIMATE CHANGE}

The integrated assessment of climate change was practiced in the 1970s and 1980s, but its conceptualization was fuzzy and it did not become an important research focus until the past few years (Rotmans \& Van Asselt 1996, Weyant et al. 1996). With this more prominent position, it has become necessary to define integrated assessment more clearly. For example, J epma \& Munasinghe (1998, p. 153-154) defined integrated assessment as 'a conceptual framework for addressing complex problems by combining a broad and transdisciplinary range of knowledge in a systematic manner.' As part of their definition of integrated assessment, Rotmans \& Van Asselt (1996) proposed a framework based on a cyclical process involving communication and consensus building among scientific, policy, and societal stakeholders. From these and other definitions that have been proposed (e.g. Parson 1996a), integrated assessment is characterized by its comprehensive scope and the integration of the many disciplines from which it draws; it differs from most disciplinary research in that it aims to assist in policy and decision making, rather than advance knowledge for its intrinsic value (Weyant et al. 1996).

The goals of integrated assessment of climate change follow directly from this conceptualization. They are to help (1) provide a systematic conceptual framework in which to structure present knowledge about climate change, (2) assess potential responses to climate change, and (3) determine the importance of climate change relative to other matters of human con- cern (Weyant et al. 1996). One possible representation of an integrated, end-to-end strategy is presented in Fig. 1 (modified from Yarnal 1996).

Integrated assessments of climate change have usually been based on formal computer models. There are several advantages to modeling the components of the climate change problem, including the ability to analyze dynamic behavior of complex systems, show interrelationships among various issues, and treat uncertainties explicitly (Rotmans \& Van Asselt 1996). Furthermore, such models promote communication among participants from diverse disciplines by imposing common language and data standards. However, integrated assessment models have weaknesses. Such models involve more precise representation of model components than current knowledge warrants (Weyant et al. 1996). Also, mathematical expressions cannot capture the complexities, subtleties, and ambiguities presented by complex nature-society interactions (Rotmans \& Van Asselt 1996). For a comprehensive summary of integrated assessment models of climate change, see Weyant et al. (1996; especially their Table 10.1).

Integrated assessments do not need to be based on formal mathematical models. Non-modeling approaches are especially relevant to research involving the right-hand side of Fig. 1, where societal and decision-making concerns are found. Non-modeling assessments range from individual authors with interdisciplinary and policy competence (e.g. Smil 1993), to collaborative interdisciplinary research teams sharing empirical knowledge (e.g. Rosenberg 1993), to expert panels contributing disciplinary expertise (Parson 1997). An important point is that there have been many projects that would be called integrated assessments today, such as the work of Rosenberg (1993), but were not because they preceded adoption of the term by the global change community. Thus, integrated assessments have been around for a long time. Furthermore, non-model methodologies and mixed model-andempirical approaches were always important, and are becoming more important to integrated assessment.

Regardless of the approach, practitioners of integrated assessment have identified many areas of concern (Morgan \& Dowlatabadi 1996, Parson 1996a,

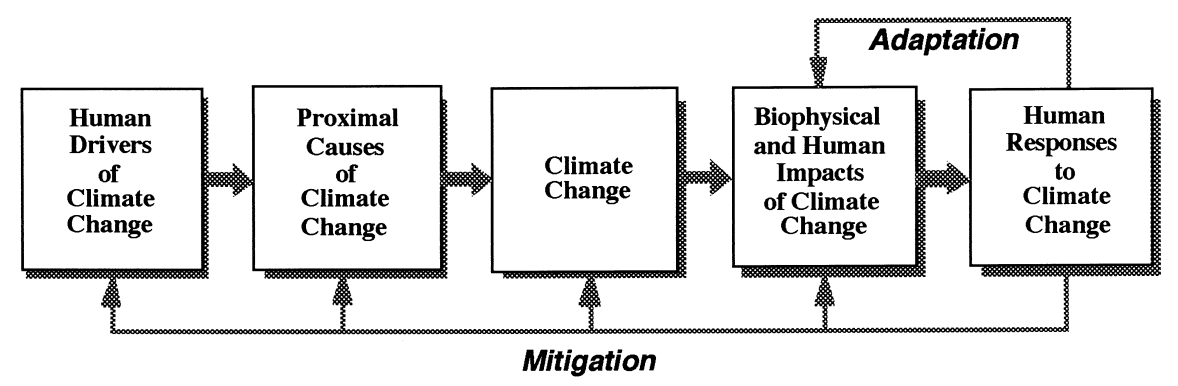

Fig. 1. Framework of a typical integrated assessment of climate change (modified from Yarnal 1996) 
Riseby et al. 1996, Rotmans \& Van Asselt 1996). Parson (1996b) summarized these worries with 3 fundamental dilemmas confronting integrated assessment. First, there is a tension between disciplinary traditions and standards and the interdisciplinary synthesis and needs of integrated assessment. Second, integrated assessments of climate change require long-term projections of society and climate, but the social sciences and climatology have limited ability to predict the future. Third, given the uncertainty and bias that cloud the scientific and political enterprises, there is no clear way to bridge the gap between scientific expertise and policy making.

One dilemma not raised by Parson (1996b), but emphasized by others (e.g. Riseby et al. 1996), is that most formal integrated assessment models of climate change suffer from problems of scale. Specifically, integrated assessment models tend to address large geographical areas and aggregated socioeconomic factors. Neither current global circulation models of climate nor integrated assessment models have the spatial resolution necessary to deal with regionally specific impacts of climate change or mitigation measures. The climate change community has been confronting the problem of translating from global to local scales for more than a decade (Kattenberg et al. 1996). However, formal integrated assessment modelers for the most part have not tried to understand the regional and local implications of global climate change.

Nevertheless, there are a few examples of geographically focused studies of the impacts of climate change, such as the sea-level rise studies conducted by Titus and collaborators in the 1980s (Titus et al. 1991). These studies alerted the climate change community and decision makers in climatically sensitive regions to the importance of assessing each region's sensitivity, vulnerability, and adaptability to climate change. From this alert, the idea of integrated regional assessment has emerged.

\section{INTEG RATED REGIONAL ASSESSMENT OF CLIMATE CHANGE}

Integrated regional assessment of climate change is in most ways the local to regional equivalent of the larger-scale integrated assessments discussed above. Integrated regional assessment is an interdisciplinary, iterative process that involves scientific, policy, and societal stakeholders. Its aim is to promote a better understanding of - and more informed decisions on how locales and regions contribute to and are affected by climate change. The intent of this section is to address a few general issues concerning integrated regional assessment. First, however, it is necessary to discuss the problems with the regional climate scenarios upon which such assessments are based.

\subsection{Regional climate scenarios}

Plausible future climates are termed climate scenarios (e.g. Mortsch \& Quinn 1996). Carter et al. (1994) identify 3 classes of scenario. First are synthetic scenarios in which climate is changed by an arbitrary, but realistic, amount. For instance, annual temperature might be increased $5^{\circ} \mathrm{C}$ for a region, while precipitation might be raised by $20 \%$. Synthetic scenarios are especially useful for exploring the sensitivity of various elements of environmental and socioeconomic systems. To illustrate, it may be useful to test the sensitivity of a region's reservoir storage to increases of 2,5 , or $8^{\circ} \mathrm{C}$ in annual temperature increase and in rises of 10 , 20 or $30 \%$ in precipitation.

A nalog scenarios use recorded or reconstructed climatic regimes to serve as analogs for future climate states. This scenario type can be temporal or spatial. The temporal type can use reconstructions of climates before the period of instrumental records, known as paleoclimatic analogs, to serve as scenarios for future climate. The other type of temporal analog scenario is instrument-based, selecting data from observed periods to represent the future climate. For instance, a recent wet year or wet decade could be used to represent future conditions in a region. Spatial analogs also use modern instrumental data, but from another region assumed to illustrate the possible changed climate of the target area. For instance along the United States East Coast, the climate of present-day South Carolina could be chosen to represent the climate of Pennsylvania with an effective doubling of carbon dioxide. Instrumental and spatial analogs can be especially useful because of the richness of modern climatic data.

Perhaps the most used scenarios of climate change are those based on the 3-dimensional, physically based GCMs (global circulation models). There are 2 basic types of GCM scenario. The most common are the equilibrium-response scenarios, more commonly called 'doubled $\mathrm{CO}_{2}$ ' or ' $2 \times \mathrm{CO}_{2}$ ' scenarios. In these experiments, modelers determine the equilibrium climate response of the model to pre-industrial levels of carbon dioxide (the ' $1 \times \mathrm{CO}_{2}$ ' scenario), then calculate the response to an effective doubling of carbon dioxide. The difference in equilibrium climate states portrays the changes caused by greenhouse-gas forcing. Such scenarios are physically unrealistic (e.g. the oceans are not dynamic, and atmospheric carbon dioxide concentrations do not double instantaneously), but because they are quick and inexpensive to run, they are useful for sensitivity experiments. 
The more realistic GCM scenarios are called transient-model scenarios. In these model runs, the annual total of carbon dioxide is increased by a authentic amount, such as $1 \%$, over a long time horizon. The model never comes to equilibrium, and it utilizes a dynamic ocean coupled interactively to the dynamic atmosphere. The main drawbacks are that transient models take weeks to months to run, output statistics are difficult to store and analyze, and the enterprise requires far greater resources than equilibrium climate modeling.

Most important to integrated regional assessment, GCMs suffer from poor spatial resolution (USGCRP 1998). The models typically employ grid increments of hundreds of kilometers, yet many (if not most) important environmental and socioeconomic processes operate at scales of tens of kilometers or much less. There are 2 interdependent reasons that GCM s cannot project regional climates accurately. First, to increase resolution to match the needs of regional assessment will require order-of-magnitude increases in computational speed and storage. Second, model physics does not currently handle regional- to local-scale processes well; parameterizations of these processes are crude and at widely separated points. The upshot is that individual point data from GCM s are of questionable accuracy, and, even if they are accurate, are too widely spaced to provide the detail needed for analysis of regional and local climate impacts.

Until GCM resolution and physics can be improved to the point that they are precise enough for regional projections, it will be necessary to develop ways to work around these limitations. Currently, climate change scientists favor numerical and empirical downscaling techniques for this purpose (Kattenberg et al. 1996). Numerical downscaling nests a higher-resolution (e.g. $108 \mathrm{~km}$ ) regional climate model in a GCM (Giorgi \& M earns 1991), yielding much-improved spatial resolution (e.g. J enkins \& Barron 1997). Empirical downscaling (Hewitson \& Crane 1996) relates observed high-resolution surface data to observed atmospheric conditions. The contemporary mathematical relationships are then applied to a GCM-based future climate to project regional climatic details at resolutions determined by the density of today's surfaceobservation network (e.g. Crane \& Hewitson 1998).

There are 2 factors that must be considered with caution in downscaling. First, the results of both numerical and empirical downscaling can only be as good as the GCM data used for the analysis. Because the GCM is providing the initial and boundary conditions for the downscaling, inaccurate GCM projections will produce inaccurate downscaled climates ( enkins \& Barron 1997). Second, the empirical downscaling approach works on the assumption that contemporary relationships between the surface and the atmosphere will be maintained in a changed climate, which may not be true. Given these difficulties, downscaling must be viewed as a stop-gap measure until modelers can generate higher-resolution GCM projections, or other work-arounds are developed.

Despite these drawbacks, integrated regional assessments to date have depended heavily on GCM scenarios; future assessments may lean too heavily on downscaled scenarios. These choices may not be defensible. As noted, GCM output is too coarse for regional assessment, and the precision of downscaling is determined by GCM output that may be highly inaccurate. Perhaps more important, GCM and downscaled scenarios only provide 1 future climate stateusually the mean. They do a poor job at producing the extremes around that mean. Yet it is quite clear that on a regional basis, extreme events will have the greatest impacts on regions (Watson et al. 1996). Synthetic scenarios and especially historical analogs may be superior to current GCM and downscaled scenarios at capturing extremes and bounding the range of climatic states that may occur with climate change.

\subsection{G eneral issues in integrated regional assessment}

Similar to climate modelers, integrated assessment modelers have yet to develop the capacity to translate from the global to the regional and local scales with precision. Still, to capture the unique characteristics of a region, and to see how those traits result in varying interactions between the region and the larger world, integrated regional assessments need to be as specific as possible. Most scientists working on integrated regional assessments have been unable or unwilling to generalize by parameterization, which the current generation of climate and integrated assessment models require. Consequently, to this point in their development, integrated regional assessments have differed from integrated assessments in that they have not usually involved formal mathematical modeling; the principal approach has entailed collaborative interdisciplinary research teams sharing empirical, disciplinary knowledge of locales and regions. Notwithstanding, model-based approaches have been and are currently being developed for integrated regional assessment. For example, regional economic models were developed for the MINK project (Rosenberg 1993) and are being applied to climate change mitigation and impact analyses in the Susquehanna River Basin (see Section 5).

Unlike larger-scale integrated assessments, regional teams have been more willing to limit the overall scope of the assessment. To help achieve the neces- 
sary geographic detail and to make the analysis more manageable, integrated regional assessments have been limited by sector (e.g. energy production) or issue (e.g. vulnerability to drought). Also, the assessments have often not been end-to-end, but have addressed various components of the climate change problem (that is, selected boxes and arrows in Fig. 1).

Although project design can, and often must, constrain the range of any one regional assessment project, it is possible to accomplish full integration by conducting multiple, parallel projects, with each project focusing on the area's climate change problems. In this case, some detailed assessments have focused on regional issues contained in the right-hand side of Fig. 1 (i.e. consequences of climate change), while others have concentrated on issues germane to the figure's left-hand side (i.e. causes of climate change). Still others can pay attention to the middle box (e.g. downscaling the effects of global climate change to local places). In due course, such multiple studies can be synthesized into a single end-to-end appraisal of the region's contributions and responses to climate change. This type of long-range strategy promotes detailed disciplinary and interdisciplinary knowledge not possible in larger-scale integrated assessments, thus contributing not only to regional integration, but to the intellectual underpinnings of the greater integrated assessment enterprise.

Integrated regional assessments concentrating on the right-hand side of Fig. 1 spotlight climate impacts. Integrated assessments of climate change impacts are an outgrowth of the seminal work of Kates (1984) on climate impact assessment. For example, Frederick (1994) and Mendelsohn \& Rosenberg (1994) discussed the embedding of climate impact analysis in the integrated assessment framework, suggesting that integrated regional assessment (without naming it as such) is a logical next step in determining climate change impacts on natural resources (Frederick et al. 1994).

In summary, integrated regional assessment gives scientists and stakeholders a framework that helps them comprehend the totality of regional variations in the causes and consequences of climate change. Understanding the regional implications of climate change is important because it is at the regional and local level that climate change mitigation must be practiced and that human impacts will be felt. However, the paradigm is immature and needs further elaboration. To demonstrate how integrated regional assessment can be useful in addressing climate change, the following 2 sections will focus on climate change impacts on the water resources of river basins - a topical area receiving considerable attention so far.

\section{IMPACTS OF CLIMATE CHANGE ON RIVER BASINS}

Much of the work on climate change and water has focused on river basins-a distinctly regional entity. Nevertheless, little of this research could be defined as integrated regional assessment. As background to the case studies presented in Section 5, which are explicitly integrated (regional) assessments of river basins, this section will discuss the suitability of river basins as units of analysis for integrated regional assessment. To illustrate further the basin-level approach to linking climate change with hydrology and water resources, the section will also give a brief overview of recent studies that have concentrated on climate change impacts on river basins.

\subsection{River basins as units of analysis}

The river basin has long been viewed as the ideal unit by which to address water resource issues comprehensively. For example, an integrated model of river basin management existed in nineteenth century America and was articulated in J ohn Wesley Powell's 1879 report A rid Lands (Wengert 1980). Later, during the middle twentieth century, the United States government encouraged an integrated regional approach to socioeconomic policy, with water-and often river basins-as the planning centerpiece (MacKenzie 1996). Today, the wise use of rivers and water resources through integrated basin management (e.g. Newson 1992) is being advocated. Integrated basin management requires intergovernmental and interdisciplinary participation by appropriate actors, a decision making process determined by all stakeholders, and legitimacy through political support, public participation, and funding (M acKenzie 1996).

Thus, there is precedent and strong support for the regional, integrated approach to dealing with water resources using the physical entity of the river basin. However, because the physical, socioeconomic, and institutional context of each basin is different, the integration of these factors is unique for each basin (Newson 1992). The paradigm of integrated regional assessment of climate change embraces that idea. It acknowledges that each basin's contributions to anthropogenic climate change will be particular, as will be the mix of mitigation options. The paradigm also recognizes that the water resource consequences of climate change - that is, the impacts and planned and unplanned responses-will also be singular.

One impediment to the perfect marriage of nature and society is that basins follow watershed dividesthat is, natural boundaries-while human activities 
are usually based on artificial political boundaries. This incompatibility means, for instance, that researchers constantly struggle with difficult-to-reconcile data, while decision makers perpetually battle jurisdictional disputes over 'poorly behaved' natural boundaries. Nevertheless, river basins are an obvious choice for regionalizing the climate change issue because, for example, water supply, river transport, and water quality studies typically use watersheds as the physical boundaries of the analysis. Flood impact research is also often restricted to basins or sub-basins. Therefore, the literature on hydrology, water resources, and climate change often uses river basins, and accordingly the regional scale, as their focus.

\subsection{Water, climate change, and river basins}

The literature on the hydrologic (physical) effects and water resource (socioeconomic) impacts resulting from climate change has become extensive. For the physical effects of climate change, most of the attention has been on simulation modeling of basin hydrologic systems (e.g. Leavesley 1994), although empirical models are still common (e.g. Cohen et al. 1996, Yates 1996). No matter which approach has been taken, considerable differences in estimated hydrologic effects exist from scenario to scenario and from basin to basin (Arnell et al. 1996). Indeed, the IPCC concluded that 'river runoff and groundwater recharge varies considerably between catchments, depending on climate regime and ... catchment characteristics' (Arnell et al. 1996, p. 327). This point underscores the need for assessing climate change impacts on the hydrology of a wide range of basins.

Basins - and therefore the regional scale-are critical to the climate change implications for water resources. The review by Zdzislaw (1996) updated the extensive climate impacts-water resource literature and highlighted water supply issues at the basin scale. It found that highly integrated, multipurpose basin management systems 'possess the robustness and resilience to withstand changes in growth, demands, and climate, and adequate institutional capacity ... to adapt to those changes' (Zdzislaw 1996, p. 475). This conclusion supports the optimistic outlook of many investigators focusing on water resources in developed countries (e.g. Rogers 1994, Stakhiv 1996).

A substantial literature on the international water resources impacts and implications of climate change for developing-country river basins has been published recently. For example, Riebsame et al. (1995) studied how climate change might influence the development trajectories of 5 international river basins: the Nile, Zambezi, Indus, Mekong, and Uruguay. Empha- sis was on integrated basin management, including reservoir operations, hydropower production, irrigation, urban water supply, flood control, and environmental protection. Although the research produced a broad range of basin impacts, the authors found that water systems tuned to climate averages and simple trends tended to fare poorly in climate change scenarios. M ost effects of climate change were negative, but (matching the conclusions of developed-country studies) there was optimism that climate change could be accommodated by good planning and management.

Countries in transition have received considerable attention, too. For instance, a special issue of Water Resources Development (1996, Volume 12, Number 2) evaluated water resource vulnerability and adaptation to climate change in several countries in transition (Strzepek \& Kaczmarek 1996). Case studies focused on basins in Poland (Kaczmarek et al. 1996), the Czech Republic (Dvorak et al. 1996), Kazakstan (Golubtsov et al. 1996), and Slovakia (Carmichael et al. 1996). It is too early to draw firm generalizations from these studies, but it is clear that more complete, integrated assessments are needed for these basins.

In sum, the above literature has greatly increased knowledge about climate change impacts on hydrology and water resources, including some important implications for decision making and policy. However, few of these studies could be termed integrated regional assessments because they were neither holistic nor sufficiently interdisciplinary in scope, and interactions between investigators was either absent or limited. Thus, the following section will present 3 case studies to provide a better appreciation of the typical scope of an integrated regional assessment.

\section{CASE STUDIES OF THE INTEG RATED REGIONAL ASSESSMENT OF RIVER BASINS}

The Mackenzie Basin Impacts Study (MBIS), The Great Lakes-St. Lawrence Basin (GLSLB) Project, and the Susquehanna River Basin Integrated Assessment (SRBIA) show 3 approaches to integrated regional assessment of river basins. Each takes a slightly different path to integration. Together, they furnish a good overview of the ways that 3 regions are using integrated regional assessments to prepare for climate change.

\subsection{The M ackenzie Basin Impacts Study}

The 6 yr MBIS, initiated by Environment Canada in 1990, fits the integrated regional assessment model perfectly (Cohen 1993, 1994, 1995, 1997a). Not only 
were impacts, vulnerability, and adaptations part of the assessment, but stakeholders were built into the process and included representatives from aboriginal groups, industry, colleges and institutes, and municipal, territorial, provincial and federal governments. A working committee, composed of representatives from aboriginal organizations, the private sector, and governments, steered the interdisciplinary effort. Especially important was the systematic approach used by MBIS. This approach incorporated qualitative information into a quantitative analysis and was designed explicitly to build a bridge between science and policy (Yin \& Cohen 1994).

$M$ any individual impact assessments (e.g. Lonergan et al. 1993) were developed to answer the project's all encompassing, integrative questions ( $Y$ in \& Cohen 1994):

-What are the implications of climate change for achieving regional resource development objectives? Should governments within the Mackenzie Basin alter their current resource-use policies or plans in anticipation of climate change?

- Does climate change increase land-use conflicts among different regional economic and social sectors? If potential conflicts are identified, how serious might they be and how could compromises be reached?

-What are the possible trade-offs for various public responses to climate change? For example, should regional parks and forests be managed to anticipate change or to preserve existing conditions?

Specific regional impacts scenarios were produced for: basin runoff quantities and timing; lake levels; ice formation, break up, and location; permafrost thaw and accompanying landslides; peatland migration; forest growth, fire frequency, and forestry potential; caribou; wheat production; tourism; oil and gas production costs; transportation systems and other infrastructure; and economic development patterns.

\subsection{The Great Lakes-St. Lawrence Basin Project}

GLSLB was another multi-year integrated regional assessment of climate change initiated by Environment Canada (Mortsch et al. 1993, Mortsch \& Mills 1996). The project ended in 1997. The goals of GLSLB were to assess the regional impacts of climate change and variability, evaluate adaptation strategies, and develop integrative methods. Like MBIS, GLSLB consisted of many linked individual investigations creating an end-to-end assessment. Studies were chosen that: addressed water management, land-use, ecosystem health, and human health issues in a multidiscipli- nary, collaborative framework; emphasized socioeconomic impacts of climate variation and change; identified and assessed adaptation options and their policy implications; proposed to communicate with stakeholders at key junctures; and utilized climate and hydrology scenarios provided by the GLSLB Project (M ortsch \& Quinn 1996).

\subsection{The Susquehanna River Basin Integrated Assessment}

SRBIA grew from the physically based, nested modeling research of the Susquehanna River Basin Experiment (SRBEX; Yarnal 1996, Lakhtakia et al. 1998). Linkages between global, regional, and local scales are a major component of SRBEX and SRBIA, and thereby form a natural connection between the physical science experiment and integrated regional assessment. The intent of SRBIA is to develop an ongoing integrated regional assessment that addresses the regional causes and consequences of global change, especially climate change. To reach that end, SRBIA is based on a modular structure (Fig. 1), with multiple, interactive components operating at one time. The intent is to add new projects as individual ones are completed. This organization promotes the flexibility needed to handle changing scientific requirements and personnel over time. It allows some studies to focus on one component, satisfying the need for indepth research, but permits other studies to be integrative across components. The focus on one geographical region-the Susquehanna River Basinensures collaboration and continual interaction among team members.

SRBIA presently consists of several related, collaborative, and interdisciplinary projects. Four concerned with climate impacts are reported here to give a sense of the diversity of studies. One project explores methodologies in integrated regional assessment, with major thrusts in downscaling, economic modeling, and complex representation of data in time and space. A second study evaluates decision-maker and public perceptions of vulnerability to climate variation and change. Surveys are being administered to groups whose activities are affected by climate (e.g. recreational fishermen and duck hunters) or whose jobs require climate information (e.g. community water system managers). A third project deals explicitly with the vulnerability of the basin's community water systems to present climate variation and climate change. Particular emphasis is given to floods and droughts, as well as to autonomous adaptation strategies and planned policy responses. A fourth investigation is determining the impacts of climate-related, water-borne diseases in the 
SRB, such as cryptosporidiosis, which can cause severe gastro-intestinal distress and in some cases death. By estimating the costs of various treatment and prevention options, they are finding that simple and inexpensive preventative measures are available, but that many people are unlikely to take advantage of them. To ensure more complete prevention, more complex and expensive measures may be necessary.

The 4 projects described here address the third, fourth, and fifth boxes of Fig. 1 (that is, the climate change, impacts, and responses modules), plus feedbacks. Other SRBIA research not discussed here concentrates on human causes of greenhouse-gas emissions and their driving forces (boxes 2 and 1 , respectively). The long-range goal of SRBIA is to develop a comprehensive picture of climate-society relationships in the basin in order to help inhabitants and decision makers prepare for climate change.

\subsection{Discussion}

The 3 case studies are not the only integrated regional assessments ever to have been conducted. There have been other integrated regional assessments of climate change impacts on river basins, such as the work of Strzepek and collaborators in Egypt (Strzepek et al. 1995, 1996, Yates \& Strzepek 1996). M oreover, river basins are not the only units covered by integrated regional assessments. For example, researchers at The Pennsylvania State University are conducting an integrated regional assessment in Bulgaria (a relatively homogenous political entity; Yarnal 1998), while scientists at the University of Arizona are carrying out one on the United States-M exico border region (where they are comparing climate change impacts in developed and developing socioeconomic systems under similar environmental constraints).

Still, the 3 case studies furnish important insights into the integrated regional assessment process. MBIS provides a model for involving stakeholders in an assessment (Cohen 1997b). The project concluded with a final workshop in Yellowknife, Northwest Territories, where results were presented and round table discussions were held to solicit stakeholder reactions. The discussions revealed that the results of the impacts research surprised many of the aboriginal, industry, and government stakeholders. Their responses to the effects of climate change ranged from a sense of helplessness, victimization, and inability to respond in a proactive way, to a strong desire to become involved in the debate at regional, national, and international levels. A series of recommendations aimed at encouraging regional stakeholders to become more involved in the climate change issue resulted from the workshop.
Perhaps the most important legacy of GLSLB was its focus on adaptation. A $n$ integral part of the project was the detailed conceptual framework of adaptation to climate developed by Smit (1993; see also Smithers \& Smit 1997). As an example of how that framework could be applied, Smit et al. (1996) conducted an empirical analysis of farmers' decision making vis-àvis climate variation. Their study suggested that climate does factor into decisions, but that its role cannot be understood without careful consideration of economic, policy, and environmental forces. Most important, their research highlighted the complex interactions of these forces with climate, and how this interaction influences individual behavior and system dynamics. The authors called for integrated regional assessments to identify significant interactions among forces and responses.

Unlike the other 2 projects, SRBIA is intended to be a continuous process instead of a finite study. The philosophy of continuous research and stakeholder interaction is partly based on the recommendations from M BIS and other projects, and partly on the definition of integrated regional assessment. SRBIA aims to use the idea of continuous process to take advantage of scientific advances and to improve communication between scientists and stakeholders iteratively. Key to improving communication over time are the surveys to determine decision-maker and public perceptions of climate variation and change. Knowing what people know and do not know about an issue allows continuous refinement of scientific and educational efforts.

In sum, the 3 projects make a persuasive case for the value of assessing the impacts of climate change at the regional scale. They show that this scale is large enough to encompass the dynamic interactions of functioning, integrated ecological and socioeconomic systems with climate, but small enough to provide the detail lost at large national and global scales. Impacts and adaptations take place at the regional and local scales. The region is also a more manageable scale to study. It is easier to gather data, those data are more homogenous, the causes and consequences are less varied, and the stakeholders have more in common at the regional scale. Finally, decision makers are more likely to care about the issues and become engaged if negative impacts (or lost opportunities from positive impacts) involve their constituents, not to mention their principal place of residence.

\section{CONCLUSIONS}

The purpose of this paper was to explain what integrated regional assessment is and how it is being used by practitioners. Integrated regional assessment is a 
category of the collaborative, multidisciplinary project that addresses the regional implications of climate change. The goal of integrated regional assessment is to determine how locales and regions contribute to and are affected by climate change, and thereby to help regional stakeholders make informed decisions on how to deal with the problem. Ideally, this type of project is comprehensive and involves scientists, decision makers, and the greater society in an interactive, iterative process. When integrated regional assessment works, it presents an ideal way of bringing together science, society, and policy to face the challenges of climate change.

Acknowledgements. I thank all those who have worked on the SRBIA and SRBEX projects, but the list is far too long to name them individually. Special thanks go to the reviewers of this paper and to Larry Kalkstein who helped improve the manuscript significantly. Funding was provided by the following: the National Aeronautic and Space Administration's Earth Observing System Grant NAGW-2686, Eric Barron, Principal Investigator; the United States Environmental Protection Agency's Office of Policy, Planning and Evaluation, Cooperative Agreement CR-824369, Ann Fisher, Principal Investigator; the National Science Foundation Human Dimensions of Global Change Grant SBR9521952, C. Gregory Knight, Principal Investigator; the United States Environmental Protection Agency's Office of Research and Development, Grant 42407-732P, Donna Peuquet, Principal Investigator; the United States Environmental Protection Agency's Office of Research and Development, Grant 824807-010, Brent Yarnal, Principal Investigator.

\section{LITERATURE CITED}

Arnell N, Bates B, Lang H, Magnuson J J , Mulholland P (1996) Hydrology and freshwater ecology. In: Watson RT, Zinyowera MC, M oss RH (eds) Climate change 1995: impacts adaptations and mitigation of climate change. Cambridge University Press, Cambridge, p 325-363

Carmichael J J , Strzepek KM, M inarik B (1996) Impacts of climate change and seasonal variability on economic treatment costs: a case study of the Nitra River Basin, Slovakia. Water Resour Dev 12:209-227

Carter TR, Parry ML, Harasawa H, Nishioka S (1994) IPCC technical guidelines for assessing climate change impacts and adaptations. Intergovernmental Panel on Climate Change, WM O/UNEP, Department of Geography, University College London, and Center for Global Environmental Research, National Institute for Environmental Studies, Japan

Cohen SJ (1993) Mackenzie Basin Impact Study: interim report \#1. Canadian Climate Center, Atmospheric Environment Service, Environment Canada, Downsview, ONT

Cohen SJ (1994) Mackenzie Basin Impact Study: interim report \#2. Canadian Climate Center, Atmospheric Environment Service, Environment Canada, Downsview, ONT

Cohen SJ (1995) An interdisciplinary assessment of climate change on northern ecosystems: the Mackenzie Basin Impact Study. In: Peterson DL, J ohnson DR (eds) Human ecology and climate change: people and resources in the Far North. Taylor and Francis, Washington, DC, p 301-316
Cohen SJ (ed) (1997a) Mackenzie Basin Impact Study: final report. Canadian Climate Center, Atmospheric Environment Service, Environment Canada, Downsview, ONT

Cohen SJ (1997b) Scientist-stakeholder collaboration in integrated assessment of climate change: lessons from a case study of Northwest Canada. Environ Model Assess 2: 281-293

Cohen S, Strzepek KM, Yates DN (1996) Climate change and water balance components. In: Kaczmarek Z, Strzepek $K M$, Somlyody L, Priazhinskaya V (eds) Water resources management in the face of climatic/hydrologic uncertainties. Kluwer Academic Publishers/International Institute for A pplied Systems Analysis, Dordrecht, p 30-45

Crane RG, Hewitson BC (1998) Doubled $\mathrm{CO}_{2}$ precipitation changes for the Susquehanna basin: down-scaling from the GENESIS general circulation model. Int J Climatol 18: $65-76$

Dvorak V, Hladny J, Kasparek L (1996) Climate change hydrology and water resources impacts and adaptation for selected river basins in the Czech Republic. Water Resour Dev 12:181-192

Frederick KD (1994) Integrated assessments of the impacts of climate change on natural resources. Clim Change 28: 1-14

Frederick KD, Goklany IM, Rosenberg NJ (1994) Conclusions, remaining issues, and next steps. Clim Change 28 : 209-218

Giorgi F, Mearns LO (1991) Approaches to simulation of regional climate change: a review. Rev Geophys 29: 191-216

Golubtsov VV, Lee VI, Scotselyas II (1996) Vulnerability assessment of the water resources of Kazakhstan to anthropogenic climate change and the structure of adaptation measures. Water Resour Dev 12:193-208

Hewitson BC, Crane RG (1996) Climate downscaling: techniques and application. Clim Res 7:85-95

Houghton JT, Meira Filho LG, Callander BA, Harris N, Kattenberg A, Maskell K (1996) Climate change 1995: the science of climate change. Cambridge University Press, Cambridge

J enkins GS, Barron EJ (1997) Global climate model and coupled regional climate model simulations over the eastern United States: GENESIS and RegCM 2 simulations. Global Planetary Change 15:3-32

J epma CJ, Munasinghe M (1998) Climate change policy: facts, issues, and analyses. Cambridge University Press, Cambridge

Kaczmarek Z, Napiorkowski J, Strzepek KM (1996) Climate change impacts on the water supply system in the Warta River catchment, Poland. Water Resour Dev 12:165-180

Kates RW (1984) The interaction of climate and society. In: Kates RW, Ausubel J H, Berberian M (eds) Climate impact assessment (SCOPE 27). J ohn Wiley and Sons, Chichester, p 3-36

Kattenberg A, Giorgi F, Grassl H, Meehl GA, Mitchell J FB, Stouffer RJ, Tokioka T, Weaver AJ, Wigley TML (1996) Climate models-projections of future climate. In: Houghton JT, Meira Filho LG, Callander BA, Harris N, Kattenberg A, Maskell K (eds) Climate change 1995: the science of climate change. Cambridge University Press, Cambridge, p 285-357

Lakhtakia MN, Yarnal B, J ohnson DL, White RA, Miller DA, Yu Z (1998) A simulation of river-basin response to mesoscale meteorological forcing: the Susquehanna River Basin Experiment (SRBEX). J Am Water Resour Assoc 34: 921-937

Leavesley GH (1994) Modeling the effects of climate 
change on water resources-a review. Clim Change 28: 159-177

Lonergan S, Difrancesco R, Woo MK (1993) Climate change and transportation in northern Canada: an integrated impact assessment. Clim Change 24:331-351

MacKenzie SH (1996) Integrated resource planning and management: the ecosystem approach in the Great Lakes Basin. Island Press, Washington, DC

Mendelsohn R, Rosenberg NJ (1994) Framework for integrated assessments of global warming impacts. Clim Change 28:15-44

Morgan M G, Dowlatabadi H (1996) Learning from integrated assessment of climate change. Clim Change 34:337-368

Mortsch L, Mills B (1996) Great Lakes-St. Lawrence Basin Project progress report \#1: adapting to the impacts of climate change and variability. Atmospheric Environment Service, Environment Canada, Downsview, ONT

Mortsch LD, Quinn FH (1996) Climate change scenarios for Great Lakes Basin ecosystem studies. Limnol Oceanogr 41:903-911

Mortsch L, Koshida G, Tavares D (1993) Adapting to the impacts of climate change and variability: proceedings of the Great Lakes-St. Lawrence Basin Project Workshop conducted on February 9-11, 1993 at Quebec City, Quebec. Atmospheric Environment Service, Environment Canada, Burlington, ONT

Newson M (1992) Land water and development: river basin systems and their sustainable management. Routledge, London

Parson EA (1996a) Integrated assessment and environmental policy making: in the pursuit of usefulness. Energy Policy 23:463-475

Parson EA (1996b) Three dilemmas in the integrated assessment of climate change. An editorial comment. Clim Change 34:315-326

Parson EA (1997) Informing global environmental policymaking: a plea for new methods of assessment and synthesis. Environ Model Assess 2:267-279

Riebsame WE, Strzepek KM, Wescoate J , Perritt R, Gaile GL, J acobs J , Leichenko R, Magadza C, Phien H, Urbiztondo BJ , Restrepo P, Rose WR, Saleh M, Ti LH, Tucci C, Yates D (1995) Complex river basins. In: Strzepek KM, Smith J B (eds) As climate changes: international impacts and implications. Cambridge University Press, Cambridge, p 57-91

Riseby J, Kandlikar M, Patwardhan A (1996) Assessing integrated assessments. Clim Change 34:369-395

Rogers P (1994) Assessing the socioeconomic consequences of climate change on water resources. Clim Change 28: 179-208

Rosenberg NJ (1993) Towards an integrated impact assessment of climate change: the MINK study. Kluwer Academic Publishers, Dordrecht

Rotmans J, Van Asselt M (1996) Integrated assessment: a growing child on its way to maturity. An editorial essay. Clim Change 34:327-336

Smil V (1993) Global ecology: environmental change and social flexibility. Routledge, New York

Smit B (1993) Adaptation to climatic variability and change. Occasional Paper 19, Department of Geography, University of Guelph

Smit B, M cNabb D, Smithers J (1996) Agricultural adaptation to climatic variation. Clim Change 33:7-29

Smithers J , Smit B (1997) Human adaptation to climatic vari- ability and change. Global Environ Change 7:129-146

Stakhiv EZ (1996) Managing water resources for climate change adaptation. In: Smith J B, Bhatti N, Menzhulin GV, Benioff R, Campos M, J allow B, Rijsberman F, Budyko M, Dixon RK (eds) Adapting to climate change: an international perspective. Springer-Verlag, New York, p 243-264

Strzepek KM, Kaczmarek Z (1996) Editorial. The United States Country Studies Program on water resources vulnerability and adaptation to climate change: scope and significance. Water Resour Dev 12:109-110

Strzepek K, Onyeji C, Saleh M, Yates D (1995) An assessment of integrated climate change impacts in Egypt. In: Strzepek KM, Smith J B (eds) As climate changes: international impacts and implications. Cambridge University Press, Cambridge, p 180-200

Strzepek K, Yates D, El Quosy D (1996) Vulnerability assessment of water resources in Egypt to climate change. Clim Res 6:89-95

Titus J G, Park RA, Leatherman SP, Weggel J R, Greene MS, Mausel PW, Brown S, Gaunt C, Trehan M, Yohe G (1991) Greenhouse effect and sea-level rise: potential loss of land and the cost of holding back the sea. Coastal Manage 19:171-204

USGCRP (1998) Our changing planet: the FY 1998 US Global Change Research Program. Committee on Environment and Natural Resources, National Science and Technology Council, Washington, DC

Watson RT, Zinyowera MC, Moss RH (eds) (1996) Climate change 1995: impacts, adaptations and mitigation of climate change. Cambridge University Press, Cambridge

Wengert N (1980) A critical review of the river basin as a focus for resources planning development and management. In: North RM, Dworsky LB, Allee DJ (eds) Proceedings of a symposium on unified river basin management. American Water Resources Association, M inneapolis, M N, p 9-27

Weyant J , Davidson O, Dowlatabadi H, Edmonds J , Grubb M, Parson EA, Richels R, Rotmans J, Shukla PR, Tol RSJ, Cline W, Fankhauser S (1996) Integrated assessment of climate change: an overview and comparison of approaches and results. In: Bruce JP, Lee H, Haites EF (eds) Climate change 1995: economic and social dimensions of climate change. Cambridge University Press, Cambridge, p 367-396

Yarnal B (1996) The policy relevance of global environmental change research. Global Planetary Change 11:167-175

Yarnal B (1998) An integrated assessment of the global warming problem in Bulgaria. In: Waterstone $M$ (ed) Human dimensions of global environmental change: a state-of-the art assessment of integrated research frameworks. Elsevier (in press)

Yates DN (1996) WatBal: an integrated water balance model for climate impact assessment of river basin runoff. Water Resour Dev 12:121-139

Yates DN, Strzepek KM (1996) Modeling economy-wide climate change impacts in Egypt: a case for an integrated approach. Environ Model Assess 1:110-135

Yin Y, Cohen SJ (1994) Identifying regional goals and policy concerns associated with global climate change. Global Environ Change 4:245-260

Zdzislaw K (1996) Water resources management. In: Watson RT, Zinyowera MC, M oss RH (eds) Climate change 1995: impacts adaptations and mitigation of climate change. Cambridge University Press, Cambridge, p 469-486 